\title{
Article
}

\section{Learning from Domestic Homicide Reviews in England and Wales}

Chantler, Khatidja, Robbins, Rachel, Baker, Victoria Louise and Stanley, Nicky

Available at http://clok.uclan.ac.uk/30570/

Chantler, Khatidja ORCID: 0000-0001-9129-2560, Robbins, Rachel ORCID: 0000-0002-6207-7703, Baker, Victoria Louise and Stanley, Nicky ORCID: 00000002-7644-1625 (2020) Learning from Domestic Homicide Reviews in England and Wales. Health and Social Care in the Community, 28 (2). pp. 485-493. ISSN 0966-0410

It is advisable to refer to the publisher's version if you intend to cite from the work. http://dx.doi.org/10.1111/hsc.12881

For more information about UCLan's research in this area go to http://www.uclan.ac.uk/researchgroups/ and search for <name of research Group>.

For information about Research generally at UCLan please go to http://www.uclan.ac.uk/research/

All outputs in CLoK are protected by Intellectual Property Rights law, including Copyright law. Copyright, IPR and Moral Rights for the works on this site are retained by the individual authors and/or other copyright owners. Terms and conditions for use of this material are defined in the policies page.

\section{CLoK}

Central Lancashire online Knowledge www.clok.uclan.ac.uk

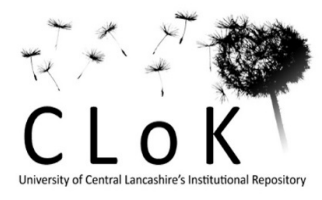




\title{
Learning from Domestic Homicide Reviews in England and Wales
}

\begin{abstract}
This paper aims to contribute to the prevention of future domestic homicide by analysing 141 domestic homicide reviews (DHRs) in England and Wales. All publicly available DHRs $(n=141)$ were retrieved from Community Safety Partnership websites in England and Wales in June 2016. Utilising a mixed methods approach, we designed templates to extract quantitative and qualitative data from DHRs. Descriptive statistics were generated by SPSS. 54 DHRs were analysed qualitatively, using N-Vivo for data management.

The findings revealed that perpetrators were aged: 16 - 82 years; with a mean average age of 41 years. Victims' ages ranged from: 17 and 91 years old; with a mean average age: 45 years. Perpetrators' mental health was mentioned in $65 \%$ of DHRs; $49 \%$ of perpetrators had a mental health diagnosis. Healthcare services, in particular, mental health services, were most likely to be involved with perpetrators. 'Movement' was identified as a key contextual feature of the 54 DHRs analysed qualitatively and this was found to interact with risk assessment, language barriers and housing problems. In conclusion, domestic violence and abuse risk assessments need to be informed by the knowledge that domestic abuse occurs across the age span. Mental health settings offer an opportunity for intervention to prevent domestic homicide. Domestic Homicide Reviews can provide valuable material for training practitioners.
\end{abstract}

Key words: domestic homicide, review, mental health, age, ethnicity, gender.

\section{What is known about this topic}

- Domestic homicide is highly gendered - the vast majority of victims are women and the vast majority of perpetrators are men 
- Domestic violence and abuse is more prevalent in younger age groups than older age groups

\section{What this paper adds}

- Perpetrator mental health is a significant feature in our dataset and mental health settings provide opportunities for intervention

- Domestic homicide occurs across the life course: in older as well as younger women

- Qualitative analysis of domestic homicide reviews illuminate contextual features of domestic homicides such as constant movement within, to or from the country, the inability to move due to a lack of housing options and a lack of appropriate interpretation arrangements.

\section{Introduction}

Multi-agency approaches to reviewing and extracting learning from domestic homicides are now operating in a number of jurisdictions including the United States, Canada, Australia, New Zealand, Portugal and England and Wales (Bugeja, Dawson, McIntyre, \& Walsh, 2015). The reports produced from these reviews offer an opportunity to identify risk and other contextual factors for domestic homicide and to critically examine interactions between victims, perpetrators and other family members and a range of agencies and professionals. This study draws on the largest sample of domestic homicide reviews (DHRs) in England and Wales analysed to date to identify a broad set of characteristics of victims and perpetrators. The findings have the potential to inform prevention strategies and practice in this field.

In England and Wales, the Homicide Index showed there were 726 homicides in the year ending March 2018 (Office of National Statistics, 2019a). Whilst the figures for this period showed an increase on previous years, the homicide rate for the year ending March 2018 was broadly similar to the homicide rate ten years ago (ibid). The Office of National Statistics (ONS) analysed 432 domestic homicides in England and Wales from 2013-15. The majority $(97 \%)$ of domestic homicide victims were female, killed by a male suspect; with over three- 
quarters $(77 \%)$ of female domestic homicide victims killed by a partner/ex-partner and 23\% killed by a family member (ONS, 2016). Domestic homicide is frequently the culmination of a pattern of domestic violence and abuse (DVA) over time in intimate partner and other familial relationships (Dobash, Dobash, Wilson \& Daly, 1992). Although a relatively rare event, the devastation inflicted on surviving family members makes it incumbent to learn from DHRs.

\section{Domestic Homicide Reviews}

In England and Wales, multi-agency fora known as Community Safety Partnerships (CSPs) have responsibility at a local level to produce crime reduction strategies. Section 9 of the Domestic Violence, Crime and Victims Act 2004, was implemented in 2011 and requires CSPs to undertake a multi-agency review after a domestic homicide and to produce a DHR. The terms of reference of DHRs are stipulated by the Home Office (Home Office, 2016a, 2018) and, in England and Wales, the definition of domestic homicide embraces both intimate partner homicides and family homicides with adult victims (ibid). The review process involves obtaining written reports from agencies who had contact with either the perpetrator and/or the victim to identify the nature of contact, any assessments made in relation to DVA, support offered or referral to another agency. It also involves talking to family and friends, as they may have additional knowledge not available to professionals.

DHRs aim to identify lessons that can be learned to prevent future homicide. However, as CSPs are locality based, learning from outside the local area can be hard to consolidate. Some regions have already begun analysing clusters of local DHRs and such studies are informative and illuminate local learning points. The Home Office conducted two swift analyses of DHRs in 2013 (54 DHRs) and in 2016 (40 DHRs). Recommendations from both studies included: increased training for healthcare professionals; improved risk assessment and improved 
responses to those with complex needs; better record keeping and missed opportunities for safeguarding children were also identified (Home Office, 2013, 2016b). Neville and Sanders (2014) undertook an in-depth analysis of 13 DHRs in the West Midlands, England, supplemented by eight stakeholder interviews. Risk assessment, the use of MARAC (MultiAgency Risk Assessment Conferences) and information sharing were highlighted in their analysis. Sharps-Jeff and Kelly (2016) analysed 32 DHRs from across England. The six most common themes found were: contact with a GP, mental health, safeguarding adults, safeguarding children, informal networks and risk assessment. Monckton-Smith, Szymanska, and Haile (2017) used media reports and DHRs to identify risk and found that stalking behaviours were present in $94 \%$ of cases analysed.

\section{Aims}

The aims of the study were to:

- To investigate the characteristics of victims and perpetrators of domestic homicides

- To analyse the relationship characteristics of victims and perpetrators

- To investigate whether informal support and/or formal agencies knew of domestic violence and abuse prior to the homicide

- To identify contextual elements of domestic homicide

A separate paper has been published with findings relating to families with children under 18 so these will not be discussed in detail here (Authors, 2018). 


\section{Methods}

All available DHRs from the 322 CSP websites in England and Wales were retrieved in July 2016. These are public documents and resulted in 141 DHRs published between July 2011 and June 2016. No ethical approval was sought as the documents are in the public domain and anonymised. Drawing on existing literature, a data extraction template was constructed and refined with use. All DHRs were then read in their entirety, capturing data on variables

relating to victim and perpetrator characteristics, relationship characteristics and history, risk factors for abuse, agency responses and notes recording context were made. Data was then further coded and entered on to an SPSS database. Basic descriptive analyses were performed across all variables to identify proportions, frequencies and averages. A further data trawl was carried out after the initial analysis to capture more detailed information regarding mental and physical health, housing and financial difficulties, immigration status, and DVA assessments. In relation to mental health, DHRs were scanned for mention of mental health issues with diagnoses by a general practitioner (GP) or other mental health practitioner also captured. Mental health was categorised according to the main disorder types within the DSM-IV-TR (American Psychiatric Association, 2000).

A qualitative analysis of a subset of all DHRs involving families with children under 18 $(n=54)$ was also undertaken, enabling identification of further themes through an interpretative reading of sections of text across the 54 DHRs (see Authors et al., 2018). This paper addresses victim and perpetrator profiles; mental health; characteristics of relationships; service and family awareness of DVA, based on 141 DHRs. Contextual features reported, particularly the theme of 'movement', draw on the qualitative analysis undertaken on the subset of 54 DHRs involving families with children under 18 years. 


\section{Findings Perpetrator and Victim Relationships}

Intimate relationships, including former partners, accounted for $77 \%$ of all cases (see Figure 3 below). Perpetrators of domestic homicide were most often the husbands or ex-husbands of victims (38\%), followed by partners/boyfriends (36\%) and sons (19\%). In most cases (62\%), the instigating factor for homicide was not cited. In the $38 \%$ of cases where it was cited, leaving or ending the relationship accounted for 29 cases (21\%). Family homicides represented $23 \%$ of cases, mostly taking the form of sons committing matricide (19\%). For both intimate partner and non-partner domestic homicide, the gendered pattern is clear.

Figure 1: Relationship to Victim, gender and relationship type
Male intimate
Female intimate
Male family
Female family

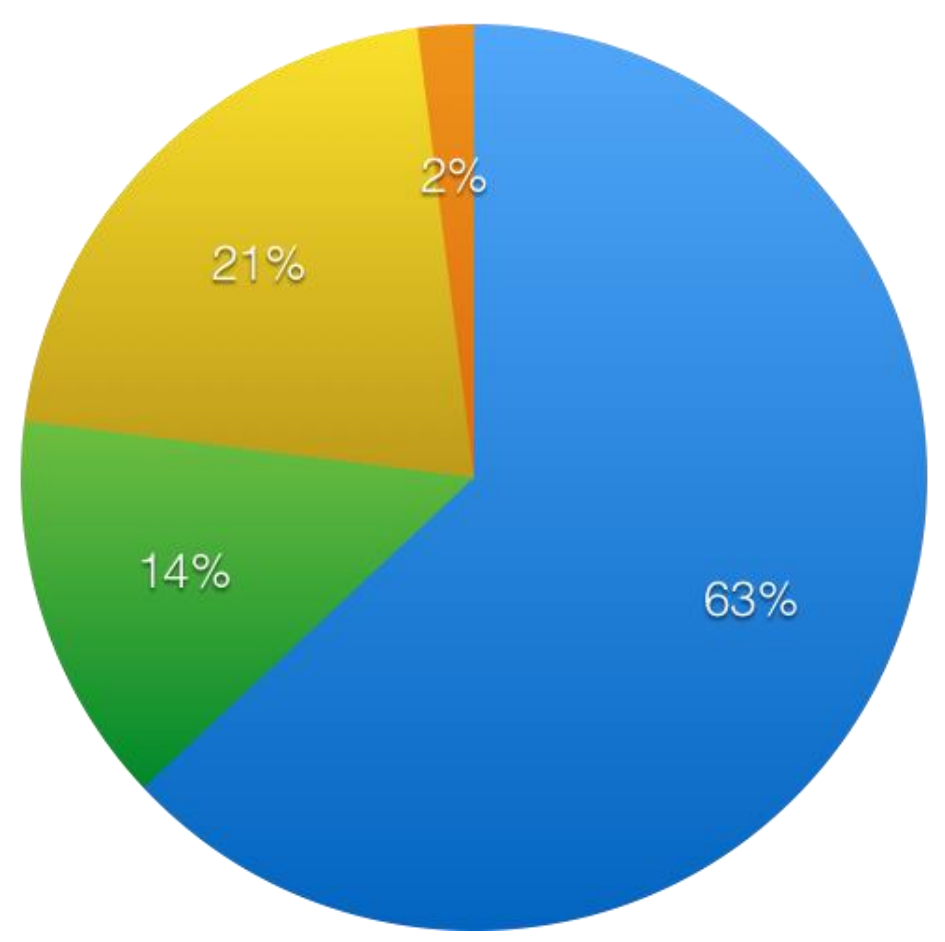




\section{Victim and Perpetrator Profiles}

Gender: In 141 DHRs, $81 \%$ of victims of domestic homicide were female; $19 \%$ were male; $86 \%$ of perpetrators were male and $14 \%$ female.

Age: Victims ranged in age from 17 and 91 years, with a mean average age of 45 (taken from primary victim where there are multiple victims). Perpetrators ranged in age from 16-82 years, with a mean of 41 years. Frequencies are presented in Figure 2:

\section{Figure 2 - Age of victims and perpetrators}

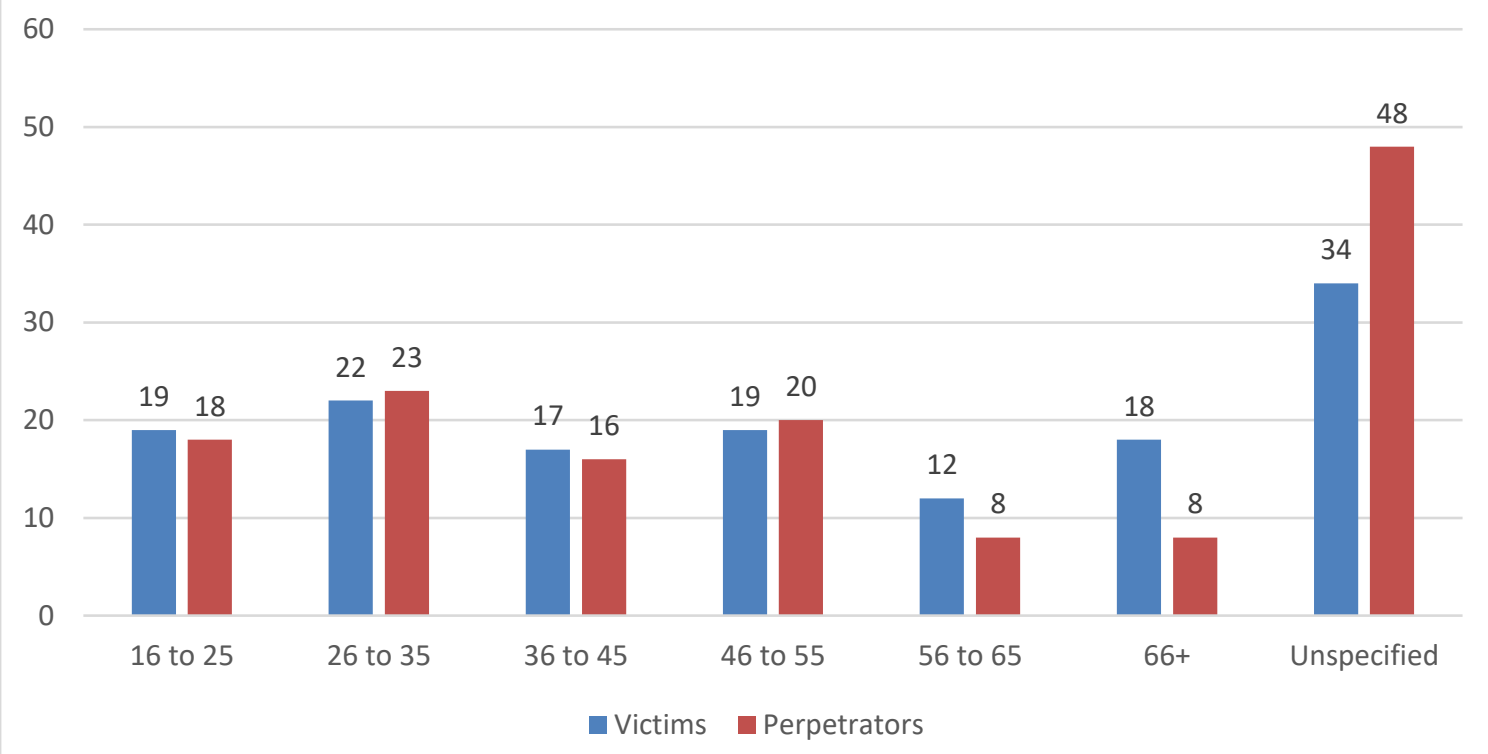

Data in respect of age was missing for just under a quarter of victims $(n=35)$ and just over a third of perpetrators $(n=48)$. Despite missing data, the mean figure from our analysis concurs with the ONS analysis of domestic homicides.

Ethnicity: Ethnicity data was available for just over a half of victims and perpetrators (72 victims and 74 perpetrators) of domestic homicide. Missing data means that findings regarding ethnicity need to be treated cautiously as it may be the case that ethnicity is largely recorded where victims or perpetrators are visibly different from the white British population, thus victims and perpetrators from other ethnicities may be falsely over represented in the 
DHR data set. Bearing this in mind, the majority of victims and perpetrators (54\% and $49 \%$ respectively) were white British. White Europeans formed the second largest category of victims (14\%), followed by Black Caribbean and Black African (11\%); South Asian (10\%); Middle Eastern (8\%) and other ethnicities (3\%). In relation to perpetrators, White British (49\%) was followed by Black African and African Caribbean (14\%); White European (14\%); Middle Eastern (12\%); South Asian (6\%) and those of mixed ethnicity (4\%).

\section{Risk Indicators}

DHRs identified potential risk indicators in victims which may have heightened vulnerability to victimisation but which might also be understood as a consequence of DVA: mental health difficulties (29\%), physical health difficulties (29\%), alcohol (25\%) and housing problems (16\%). Just over a quarter (26\%) also had a prior history of DVA, largely as victims but were also identified as perpetrators in a few cases. Perpetrators' histories revealed a range of potential risk indicators which may have enhanced risk of perpetrating DVA. The single largest category was previous violent behaviour (70\%), followed by mental health problems (64\%), alcohol problems (48\%), drug problems (37\%), and physical health problems (18\%). Prior to the homicide, a third (33\%) of perpetrators had allegations against them of physical violence to a previous partner and nearly a third (32\%) had allegations of prior violence against the victim themselves. These findings align with Dobash's and Dobash's (2015) homicide findings regarding the importance of a history of previous DVA.

Of the potential risk indicators identified above, mental health is discussed in more detail below. 


\section{Mental Health}

Perpetrators' mental health was a striking feature in our dataset. $18 \%$ of victims and $49 \%$ of perpetrators had diagnosed mental health problems. Figure 3 below illustrates the frequencies of mental health diagnosis of both victims and perpetrators:

Figure 3: Mental Health Diagnoses of Domestic Homicide Review Victims and Perpetrators

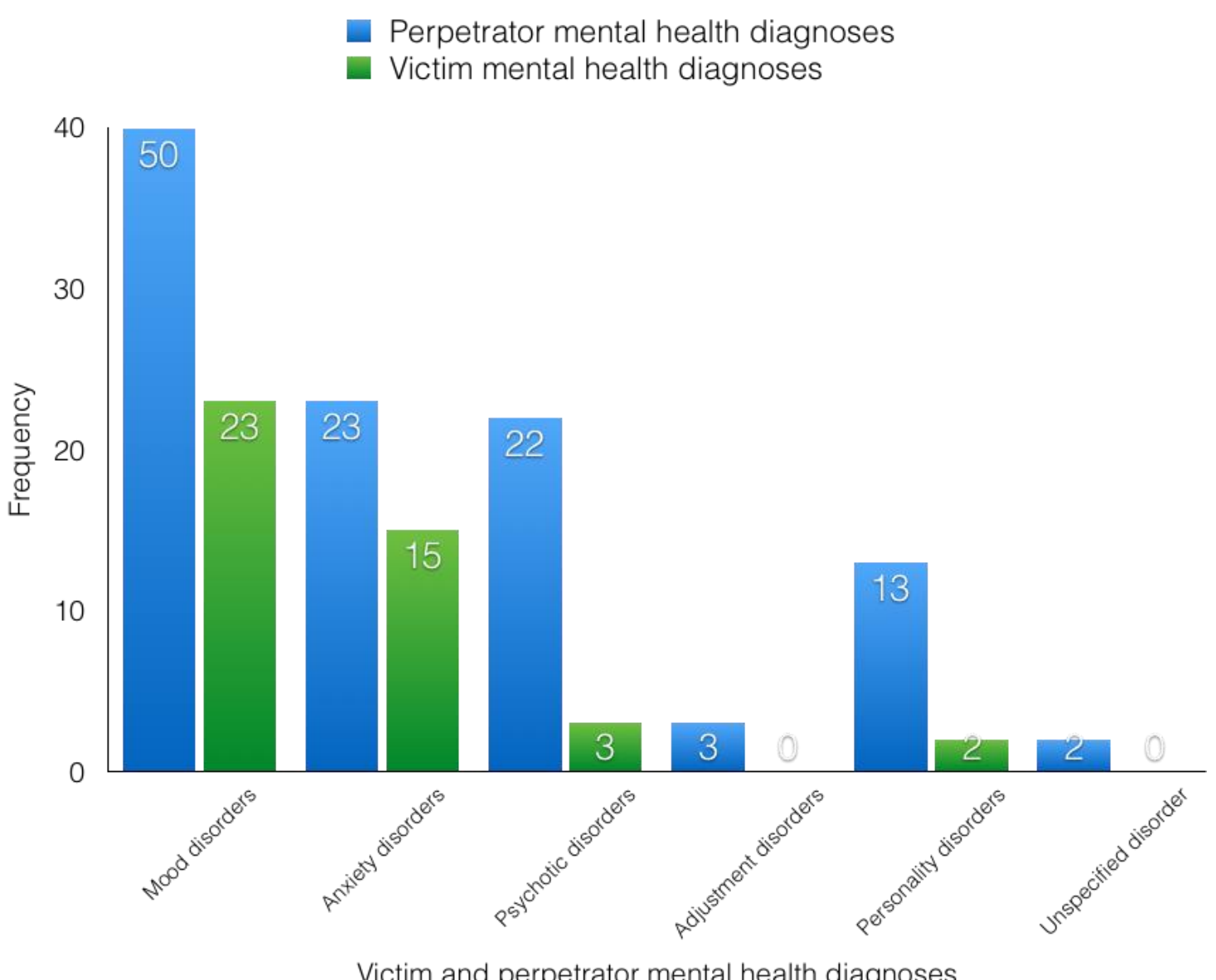

Mood and anxiety disorders formed the bulk of mental health diagnoses. Victims experienced: depression, anxiety, psychosis, and personality disorders, with depression and anxiety being the most commonly reported. Nearly two-thirds (64\%) of victims with a diagnosis experienced more than one disorder - either consecutively over the life course or concurrently. Perpetrators' mental health problems were further complicated by the presence of substance misuse, with just under a quarter $(23 \%)$ of perpetrators experiencing both drug 
misuse and mental health problems, and just over a quarter (26\%) experiencing both alcohol misuse and mental health problems. A proportion of homicides (13\%) were carried out by individuals experiencing episodes of acute mental health difficulty, who were later placed under hospital orders. Manslaughter with diminished responsibility accounted for $18 \%$ of convictions.

\section{Service involvement and awareness}

In half (50\%) of the cases, support agencies such as the police (47\%), health (25\%), housing $(12 \%)$, education $(5 \%)$, children's social care $(15 \%)$, adult social care $(4 \%)$ and domestic violence organisations $(1 \%)$ were aware that DVA was present within the victim-perpetrator relationship. An awareness of this did not automatically result in a service to victims. Table 1 shows which services provided direct services to either victims or perpetrators and highlights the high levels of health service involvement. Perpetrators were often in receipt of mental health services, but also received services for their physical health and substance misuse. Housing support services were involved with nearly a fifth of all victims whilst specialist DVA services were provided to only $10 \%$ and only $9 \%$ were provided with services by Multi-Agency Risk Assessment Conference (MARACs) which should assess all high risk domestic abuse cases in their locality.

Table 1: Services Provided to Victims and Perpetrators

\section{Support service}

DVA specific services

Perpetrator programmes

Police support (e.g. injunctions, monitoring home)

Refuge
Victims

Perpetrators 
Housing support services (any)

Legal support/advice

Mental health services

Physical health care

Education

Women's Centre

Substance misuse services

Children's Centre services

Adult social care

MARAC
$26(18 \%)$

$12(9 \%)$

$20(14 \%)$

$68(48 \%)$

$56(40 \%)$

$35(25 \%)$

$5(4 \%)$

$3(2 \%)$

$12(9 \%)$

$22(16 \%)$

$3(2 \%)$

$9(6 \%)$

$13(9 \%)$

\section{Family/friend involvement and awareness.}

In nearly half the cases (45\%), victims' and/or perpetrators' family members or friends were aware of DVA within the relationship, with the remaining DHRs either not mentioning others' awareness (17\%) or stating that neither family nor friends knew of any abuse (38\%). This level of awareness is close to the $50 \%$ of cases where professional support services were aware of DVA. In total, DVA was known to either family/friends or professional services in $64 \%$ of cases. The remaining cases $(36 \%)$, involved relationships where either DVA was not a characteristic, it was hidden, or those who were aware of it were not spoken to by the review team. Although reported very rarely, only 17 reports (12\%) referred to victims who received frequent family or peer support, and this figure was the same for infrequent friend and/or family support. Only four DHRs (3\%) explicitly stated that victims received no support from friends or family. 


\section{Movement}

Among the 54 DHRs analysed qualitatively, the overarching theme of 'movement' was identified in over half the cases (28) where it took different forms. These included: i) cases involving migrants from the European Union $(\mathrm{EU})(\mathrm{n}=5)$; ii) victims and/or perpetrators from outside the EU (n=9); iii) intra-country movement ( $\mathrm{n}=7)$ and iv) inability to move or having no fixed abode $(n=7)$. Three key inter-linked sub-themes emerged from this analysis: $i)$ risk assessment; ii) language barriers; iii) housing problems.

\section{Risk Assessment}

Improving risk assessment was discussed in most DHRs where movement was identified. Within the full dataset of 141 cases, just over a third (35\%) had been assessed using a DVA assessment tool, rating cases at the following risk levels: standard/low (23\%), medium (16\%), high (9\%) or very high (2\%). Assessments were infrequently referred to (MARAC), with only 13 cases (9\%) receiving support through MARAC. Of those cases where DVA was known to services, nearly half of victims $(48 \%)$ had not received a formal DVA risk assessment at the time of the victim's death.

DHR134 illustrates key dimensions found in several other cases. The case involved an Eastern European couple who had been in a 12-year relationship and had a ten-year-old child. There had been two recorded serious assaults on the victim by her partner prior to the homicide. On both occasions, the perpetrator left the country after each of the assaults but returned later. The perpetrator made threats to kill his partner which were reported to Children's Social Care (CSC) by the child. The family were referred to the local MARAC after the first assault, but not the second. The victim was abducted by her partner and her dead body was found in Eastern Europe a couple of months later. The DHR stated: 
None of the agencies asked [the victim] about her life in [Eastern Europe] prior to moving to [name of town in the UK]. It was as though her life had begun on the day she arrived in the UK. Had the police or children's social care sought information about [the victim's] life in [Eastern Europe] they would have learnt that there had been a series of incidents prior to her arrival in the UK. This information would have informed their risk assessments. (DHR134, p.46, Overview Report).

This highlights the value of enquiring into the pattern of the relationship rather than dealing with assaults on an incident by incident basis. Further, this DHR identified a lack of police knowledge of computer systems between the Police National Database and the UK Border Agency database. Perpetrators may cross borders to evade detection and information sharing may need to take place across international as well as organisational boundaries.

The issue of movement was central in this case. Once the perpetrator left the country, it was assumed that the victim was safe and so no adequate protection was put in place should her abusive partner return to the UK: 'No agency considered a contingency plan should the exhusband return, even though that was an established pattern' (DHR134, p.8, Executive Summary). The temporary absence and movement of the perpetrator obscured the potential for his return and to inflict further harm.

\section{Language Barriers}

DHRs 043, 134 and 120 involved Eastern European migrants with limited/no English language. In DHR 134, an Independent Domestic Violence Advocate (IDVA) with a shared linguistic background was allocated to the victim, but it is unclear how other agencies interacted with the victim. The victim had contacted all the relevant authorities but there were discrepancies in basic record keeping between agencies. For example, her name was spelt in different ways by agencies so preventing an overview of her case across agencies and hampering risk assessment. 
In DHR 120, good practice was evidenced as interpreters were used, but the DHR noted a significant challenge surrounding 'the dependency on interpreters who may be unfamiliar with domestic violence or have a different cultural perspective of family violence' (DHR120, p.11, Executive Summary). These issues were also evident in cases involving migrants from outside the EU. In one DHR, the couple's 12-year-old child and male family friend were used as interpreters and the DHR states:

There is evidence throughout this review that consideration of the family's linguistic needs were not taken into account when accessing services as they should have been. Opportunities to seek a [relevant language] interpreter were often missed. On many occasions [the child] was used as an interpreter for his mother and father, or sometimes a family friend. The vulnerability of both [the victim] and [her child] was often not considered or recognised. (DHR132, p.7, Executive Summary)

The unsuitability of using children as interpreters is well documented in the professional practice literature (Chand, 2005; Sawrikar, 2015); prompting questions about how and why this practice continues. The use of a male family friend as interpreter was also identified as problematic due to his gender and the cultural inappropriateness of discussing DVA with a male friend of her husband: This is particularly the case given the gender of the friend who interpreted, his primary relationship being with [the perpetrator] and the cultural expectations of him in a domestic violence situation' (DHR132, p.98, Overview Report). These examples highlight the importance of using interpreters trained in DVA with the ability to interpret discussion of taboo topics.

\section{Housing Problems}

Housing difficulties were identified for $55 \%$ of all victims in the total sample, with nearly a quarter $(22 \%)$ experiencing inconsistent or temporary accommodation and nearly a fifth (18\%) 
experiencing homelessness. Just over half $(51 \%)$ of all perpetrators had housing difficulties, with nearly a quarter $(22 \%)$ experiencing inconsistent or temporary accommodation and a quarter (25\%) experiencing homelessness. Qualitative analysis found that families characterised by frequent moves and transient living presented difficulties for services. One DHR described the challenges the numerous moves of this couple (White British) presented for professionals:

They had multiple aliases and addresses. The address chronology suggests that they sometimes moved back and forth between addresses rather than moving from one to the next in a linear fashion. [The alleged perpetrator] had poor literacy levels. All these factors increased the challenge to professionals in communicating with them and in identifying and assessing risk (DHR113, p.7, Executive Summary)

Some DHRs also identified how changes of address contributed to a lack of free-flowing information between local authority, police and health services areas to enable the continuity of care, which might have enhanced support and protection. For example, in DHR060, a married couple with three children moved within one geographical area in North-East England five times, then moved to a city in North-West England and the victim and the children then moved from there to temporary accommodation before moving to a permanent address. The frequent moves spanning different police force jurisdictions culminated in:

'... a request from [Police Force A] to [Police Force B] to check on the welfare of a vulnerable woman and her three children did not happen despite [Police Force A] providing the correct address to [Police Force B]. ...the job was passed between divisions, the entries on the logs grew and no one spotted that the ultimate information they were seeking [the victim's whereabouts] was recorded at the beginning of the entries.' (DHR060, p.36-37, Overview Report). 
In contrast, a small proportion of couples were unable to physically separate due to a lack of housing options and were forced to reside in the same property. One victim's sister stated that 'the concept of establishing a separate household within the home' was flawed as it magnified tensions within the relationship (DHR 027, pg. 14, Overview Report). This DHR recommended: Separation should be seen as a process which can magnify risk factors, not a safety plan in itself. All agencies..., should be advised that the period around separationespecially while a couple still share a home- should be seen as a period of enhanced risk of violence, and should advise service users accordingly. (DHR027, p.14, Overview Report)

\section{Discussion}

The discussion below addresses four key dimensions: age, ethnicity, mental health and movement and considers how they might inform risk assessment in the field of DVA.

Age: Victims' and perpetrators' ages ranged from 16-91 years with a mean age of 41 years for perpetrators and 45 years for victims. Domestic homicide thus occurs across the life course, giving rise to two key points about how the age of DVA victims is recorded and understood. Firstly, in relation to recording, the latest Crime Survey for England \& Wales (CSEW) reveals that the prevalence of DVA is highest for women aged 20-24 compared to older women aged 55-59 (ONS, 2019b). The CSEW cut-off at 59 is based on the assumption that women over 60 will be less familiar with the self-completion methodology used for the DVA module but it is problematic as it acts to exclude older women from this important data set. Further, in England and Wales, the distinction between DVA and elder abuse serves to camouflage DVA in older women (Author et al., 2016).

Secondly, for practitioners, the CSEW figures may suggest that domestic homicide is more likely to be experienced by younger women. Carthy and Taylor (2017) suggest that a service 
emphasis on DVA in younger adults may undermine confidence and knowledge of services in older women and deter help seeking. ONS domestic homicide data also confirms that female victims over the age of 75 are disproportionally represented (13\%) compared to their population profile (9\%) (ONS, 2016). Dobash and Dobash's (2015) study also highlights the need for further research on older female victims of domestic homicide. Comparing DVA and domestic homicide age related data underscores that DVA and domestic homicide is experienced across every age group and risk assessment tools need to reflect experience over the life course.

Ethnicity: Whilst the proportion of those from groups other than white British in our DHR sample may appear high (compared to their population profiles), this does not necessarily reflect a heightened prevalence of domestic homicide in minority ethnic groups. Recording of ethnicity was patchy in DHRs published before 2017 but this should improve following recent guidance stipulating that this should be recorded (Home Office, 2018). Further research is necessary to establish the role of ethnicity in domestic homicide. An ONS comparison of homicides and domestic homicides found that among females victims of domestic homicide were less likely to be White (76\% compared with $86 \%$ of female victims of non-domestic homicide), and more likely to be Asian (12\%, compared with $7 \%$ of female non-domestic homicide victims) (ONS, 2016b). However, caution still needs to be exercised as illustrated by a recent Norwegian study by Vatner, Friestad and Bjorkly (2017). They investigated the over-representation of immigrant victims and perpetrators in Norway over a 12-year period and compared the characteristics of these intimate partner homicides with the native majority perpetrators of such homicides. They concluded that other factors such as higher rates of unemployment, racism and related social disadvantage may be more salient than ethnicity. The UK, like Norway, has long standing evidence of social inequality amongst minority ethnic groups (Cabinet Office, 2017) so an analysis at the intersection of class and 
ethnicity in domestic homicide is essential to ascertain whether ethnicity can be considered an independent variable or risk factor.

Mental Health: Our finding regarding the high incidence of mental health problems in perpetrators is surprising given that victims experiencing DVA are more likely to experience mental health problems related to or exacerbated by experiences of DVA (Howard, 2012). The most common diagnostic combination identified in perpetrators was co-morbid depression and anxiety. The Adult Psychiatric Morbidity Survey (APMS), reported one in six people (over the age of 16) surveyed in England met the criteria for a common mental disorder (CMD) in 2014 (APMS, 2016). APMS (2016) (as in previous surveys) found that women were more likely than men to have reported CMD symptoms. However, what is distinctive in our sample is that many more men (mainly perpetrators) were diagnosed with common mental disorders (mood and anxiety disorders) than women (mainly victims).

The high frequency of common mental health disorders related to perpetration of domestic homicide in our sample needs to be contextualised against studies that report on mental health and perpetration of DVA. Hester Eisenstadt, Jones, and Morgan (2017) found that $71 \%$ of 48 perpetrators who had completed the Drive perpetrators programme had mental health issues. Hester et al., (2015) also reported that DVA is experienced or perpetrated by a large minority of men presenting to general practice who were more likely to have current symptoms of depression and anxiety. Oram, Trevillion, Khalifeh, Feder, and Howard's (2013) review found that psychiatric disorders (depression, generalised anxiety disorder and panic disorder) were associated with high prevalence and increased odds of having ever been physically violent against a partner. Button, Angel and Sherman (2017) analysed data from Leicestershire's police and found that it was five times more likely that offenders charged with domestic homicide had prior suicidal warning markers than did all other offenders. The 
relationship between mental health disorders and a history of perpetrating DVA clearly warrants further exploration but this study suggests that it may be an indicator of high risk of perpetration of domestic homicide.

Movement: Movement was conceptualised in this study as movement across borders (migration) with its attendant issues (e.g. English as a second language); temporary movement or absence of perpetrators; movement of information between agencies; frequent and transient housing moves as well as the inability to move due to a lack of alternative housing. Movement is often a means of escaping DVA but the knowledge that victims who move can remain at risk from ex-partners (Authors, 2012; Humphreys \& Thiara, 2003) does not seem to have informed professional intervention in many of these cases. Movement (or inability to move) is a factor that could usefully be incorporated into DVA risk assessment. The theme of 'movement' highlights the learning opportunities offered by DHRs and the importance of social context for assessing risk.

\section{Limitations}

There will have been additional domestic homicides during the study period, which were not yet published by July 2016 or were withheld due to the perceived sensitivity of the case (Bridger, Strang, Parkinson, \& Sherman, 2017). Further, some information is deliberately vague in DHRs to preserve the confidentiality of families. However, we are confident that our analysis in relation to key demographics map on to the ONS data. Although DHRs are a rich source of information, they are not produced for research purposes. Extracting even basic information such as demographic data is often difficult; understanding the context and dynamics of family relationships is complex. The variable quality of DHRs also impacts on what data can be extracted. DHRs offer genuine opportunities for reflection and improving 
service responses to DVA victims, but there is always the potential for agencies to protect their own reputations rather than engage in a process of reflective learning.

The absence of a potential risk factor in a case does not necessarily mean it was not present. In many of the DHRs, the friends and families of victims and perpetrators declined to participate, limiting the identification of risk factors to the service records of victim and perpetrator interactions and documented disclosures to services.

\section{Conclusions}

The analysis of DHRs offers huge potential to share the learning culled from them nationally and potentially internationally. More precise recording of key characteristics within DHRs would greatly enhance research and the development of risk assessment models. Detailed research is required which not only illuminates general patterns of domestic homicide, but which also employs a more granular and finely tuned analysis, in relation to sub-sets of domestic homicide victims and perpetrators.

Key findings include perpetrators' mental health disorders, housing problems, service responses to victims' lack of English language skills and movement across borders and within country. The research literature is clear about the mental health impacts of DVA for victims (Howard, 2012). Our study illustrates the importance of extending this understanding to perpetrators of domestic homicide as $49 \%$ of perpetrators in our sample had diagnosed mental health issues, strongly suggesting that mental health services are a prime setting to discuss DVA with perpetrators. The range of agencies that victims or perpetrators had contact with prior to the homicide indicates potential audiences for disseminating learning from DHRs which should be aimed at improving identification and risk assessment in relation to DVA. 
The findings on age should help to inform policy and practice of the high risk of domestic homicide for older women and have implications for adult social care services. The relationship between ethnicity and domestic homicide requires further research as although the proportions for groups other than White British may appear high (compared to their population profiles), as has been argued above this does not necessarily reflect a heightened concern. The biggest single risk factor for victimisation is gender as the majority of domestic homicides victims are women. Our qualitative analysis of themes such as housing needs, language barriers and movement across and within national borders begins to provide information that could inform training on domestic homicide prevention for a wide range of services and practitioners. The narrative format of DHRs and the detailed, incident-full stories they tell make them powerful training tools and their potential to drive and improve policy and practice in the field of domestic violence and abuse should be exploited to the full.

\section{References}

APMS. (2016). Adult Psychiatric Morbidity Survey: Survey of Mental Health and Wellbeing, England, 2014. Retrieved from: http://digital.nhs.uk/catalogue/PUB21748

American Psychiatric Association (2000) Diagnostic and statistical manual of mental disorders (4th ed., Text Revision).

Author and another, (2017).

Author et al, (2016).

Authors (2018).

Bridger, E., Strang, H., Parkinson, J., \& Sherman, L. W. (2017). Intimate partner homicide in England and Wales 2011-2013: Pathways to prediction from multi-agency domestic 
homicide reviews. Cambridge Journal of Evidence-Based Policing, 1(2-3), 93-104.doi: $10.1007 / \mathrm{s} 41887-017-0013-\mathrm{Z}$

Bugeja, L., Dawson, M., McIntyre, S. J., \& Walsh, C. (2015). Domestic/family violence death reviews: An international comparison. Trauma, Violence, \& Abuse, 16(2), 179-187.doi: $\underline{10.1177 / 1524838013517561} \underline{10.1177 / 1524838013517561}$

Button, I. M., Angel, C., \& Sherman, L. W. (2017). Predicting domestic homicide and serious violence in Leicestershire with intelligence records of suicidal ideation or self-harm warnings: A Retrospective analysis. Cambridge Journal of Evidence-Based Policing, 1(2-3), 105-115.doi: 10.1007/s41887-017-0009-8

Cabinet Office (2017). Race Disparity Audit: Summary Findings from the Ethnicity Facts and Figures website, Cabinet Office: London. Retrieved from:

https://assets.publishing.service.gov.uk/government/uploads/system/uploads/attachment_data /file/686071/Revised_RDA_report_March_2018.pdf

Chand, A. (2005). Do you speak English? Language Barriers in Child Protection Social Work with Minority Ethnic Families, The British Journal of Social Work, Volume 35, Issue 6, 1 September 2005, Pages 807-821, https://doi.org/10.1093/bjsw/bch205

Community Safety Partnerships (2011). Retrieved from: https://data.gov.uk/dataset/community-safety-partnerships-contacts

Dobash R.E.\& Dobash R.P. (2015). When Men Murder Women, Oxford: Oxford University Press.

Dobash, R.P., Dobash, R.E., Wilson, M. and Daly, M. (1992). "The myth of sexual symmetry in marital violence" Social Problems. 39 (1): 71-91.doi: 10.2307/3096914 
Hester, M., Eisenstadt, N., Jones, C., and Morgan. K. (2017) Evaluation of the Drive Project - a pilot to address high-risk perpetrators of domestic abuse Year 1 Feasibility Study.

Retrieved from:

http://driveproject.org.uk/wp-content/uploads/2017/11/Evaluation-of-the-Drive-Project-Year$\underline{1-F e a s i b i l i t y-S t u d y . p d f}$

Hester, M., Ferrari, G., Jones, S. K., Williamson, E., Bacchus, L. J., Peters, T. J., \& Feder, G. (2015). Occurrence and impact of negative behaviour, including domestic violence and abuse, in men attending UK primary care health clinics: a cross-sectional survey. BMJ Open 5(5), 2015; 5:e007141.doi:10.1136/bmjopen-2014-007141:

http://bmjopen.bmj.com/content/bmjopen/5/5/e007141.full.pdf

Home Office (2013). Domestic Homicide Reviews: Common themes identified as lessons to be learned. London, Home Office. Retrieved from:

http://data.parliament.uk/DepositedPapers/Files/DEP2013$\underline{\text { 1881/Domestic_Homicide_Review_-_Common_themes_v2_2_.pdf }}$

Home Office (2016a). Multi-agency Statutory Guidance for the Conduct of Domestic Homicide Reviews, London, Home Office. Retrieved from:

https://assets.publishing.service.gov.uk/government/uploads/system/uploads/attachment_data /file/575273/DHR-Statutory-Guidance-161206.pdf

Home Office (2018). Multi-Agency Statutory Guidance for the Conduct of Domestic Homicide Reviews, London, Home Office. Retrieved from: https://assets.publishing.service.gov.uk/government/uploads/system/uploads/attachment_data /file/97881/DHR-guidance.pdf 
Home Office (2016b). Domestic Homicide Reviews: Key findings from analysis of domestic homicide reviews. London, Home Office. Retrieved from:

https://assets.publishing.service.gov.uk/government/uploads/system/uploads/attachment_data /file/575232/HO-Domestic-Homicide-Review-Analysis-161206.pdf

Howard, L. M. (2012). Domestic violence: its relevance to psychiatry. Advances in Psychiatric Treatment, 18(2), 129-136.doi: https://doi.org/10.1192/apt.bp.110.008110

Humphreys, C. and Thiara, R. (2003) Neither Justice nor Protection: women's experiences of post-separation violence, Journal of Social Welfare and Family Law 25(3), 195-214. DOI:

Monckton-Smith, J., Szymanska, K., and Haile, S (2017). Exploring the Relationship between Stalking and Homicide. Suzy Lamplugh Trust. Retrieved from: http://eprints.glos.ac.uk/4553/1/NSAW\%20Report\%2004.17\%20-\%20finalsmall.pdf

Neville, L. and Sanders-McDonagh, E. (2014). Preventing Domestic Violence and Abuse: Common Themes and Lessons Learned from West Midlands' DHRs. London, Middlesex University London. Retrieved from: http://eprints.mdx.ac.uk/14418/3/Final\%20Report\%20September\%202014.pdf ONS (2012). Ethnicity and National Identity in England and Wales: 2011. Retrieved from: https://www.ons.gov.uk/peoplepopulationandcommunity/culturalidentity/ethnicity/articles/et hnicityandnationalidentityinenglandandwales/2012-12-11

ONS (2016). Homicide: Findings from analyses based on the Homicide Index recorded by the Home Office covering different aspects of homicide. Retrieved from: https://www.ons.gov.uk/peoplepopulationandcommunity/crimeandjustice/compendium/focus onviolentcrimeandsexualoffences/yearendingmarch2015/chapter2homicide\#focus-ondomestic-homicides 
ONS (2019a). Homicide to year ending March 2018. Retrieved from:

https://www.ons.gov.uk/peoplepopulationandcommunity/crimeandjustice/articles/homicidein englandandwales/yearendingmarch2018

ONS (2019b). Domestic abuse: findings from the Crime Survey for England and Wales: year ending March 2018. Retrieved from:

https://www.ons.gov.uk/peoplepopulationandcommunity/crimeandjustice/articles/domesticab usefindingsfromthecrimesurveyforenglandandwales/yearendingmarch2018

Oram, S., Trevillion, K., Khalifeh, H., Feder, G., \& Howard, L. M. (2013). Systematic review and meta-analysis of psychiatric disorder and the perpetration of partner violence.

Epidemiology And Psychiatric Sciences, 1-16.doi: 10.1017/S2045796013000450

Sawrikar, P. (2015) 'How effective do families of non-English speaking background (NESB) and child protection caseworkers in Australia see the use of interpreters? A qualitative study to help inform good practice principles'. Child \& Family Social Work, 1-11. doi:

$10.1111 /$ cfs. 12088

Sharps-Jeffrey, N. and Kelly, L. (2016). Domestic Homicide Review (DHR) Case Analysis: Report for Standing Together. London, Standing Together and London Metropolitan University. Retrieved from:

http://www.standingtogether.org.uk/sites/default/files/docs/STADV_DHR_Report_Final.pdf

Trevillion, K., Williamson, E., Thandi, G., Borschmann, R., Oram, S., \& Howard, L. M. (2015). A systematic review of mental disorders and perpetration of domestic violence 
among military populations. Social Psychiatry and Psychiatric Epidemiology, 50(9), 13291346.doi: 10.1007/s00127-015-1084-4

Vatnar, S. K. B., Friestad, C., \& Bjørkly, S. (2017). Intimate partner homicide, immigration and citizenship: evidence from Norway 1990-2012. Journal of Scandinavian Studies in Criminology and Crime Prevention, 18(2), 103-122.doi: 10.1080/14043858.2017.1394629 